\title{
Comportamento de Leguminosas (Adesmia, Lotus, Trifolium) em Mistura com Festuca1
}

\section{Simone Meredith Scheffer-Basso ${ }^{2}$, Marice Cristine Vendrúsculo ${ }^{3}$, Karinne Baréa ${ }^{4}$, Rubens Cácio Benincá ${ }^{5}$, Ricardo Lubenow ${ }^{6}$, Dileta Cecchetti ${ }^{7}$}

\begin{abstract}
RESUMO - A introdução de leguminosas hibernais é uma das práticas mais importantes para incrementar a quantidade, a qualidade e a sustentabilidade de pastagens perenes no Sul do Brasil. Durante os anos de 2000 e 2001, foi avaliado o comportamento de seis leguminosas temperadas (Adesmia latifolia - nativa, Lotus corniculatus, L. subbiflorus, L. uliginosus e Trifolium repens - cv. Yi e Regal), em mistura com festuca (Festuca arundinacea). Entre a semeadura e o último corte decorreram 475 dias, sendo realizados seis cortes: no outono-inverno/2000, foi feito um corte; na primavera-verão, três e, no outono-inverno/2001, dois cortes. Os intervalos entre cortes variaram entre 43 a 91 dias, sendo menores na estação estival. No total do período experimental obtiveram-se, na média das misturas, $15.038 \mathrm{~kg} / \mathrm{ha} \mathrm{de} \mathrm{MS,} \mathrm{sendo} \mathrm{que,} \mathrm{na} \mathrm{primavera-}$ verão foram produzidos cerca de $54 \%$ desse total, com taxa de crescimento média de $46 \mathrm{~kg} / \mathrm{ha} / \mathrm{dia}$ de MS. Nos meses de outono-inverno de 2000 e 2001, foram obtidas taxas de 22 e $24 \mathrm{~kg} / \mathrm{ha} / \mathrm{dia}$ de MS. O cornichão e o trevo-branco cv. Yi foram as leguminosas mais produtivas, sendo que a primeira destacou-se na primavera-verão (3.500 kg/ha de MS) e a última participou com 86,3\% na mistura no outono-inverno/2001, com 2.300 $\mathrm{kg} / \mathrm{ha}$ de MS. As misturas contendo essas leguminosas apresentaram a menor quantidade de invasoras e produziram, respectivamente, 13.663 e $11.184 \mathrm{~kg} / \mathrm{ha}$ de MS, sendo 82 e $71 \%$ desses totais compostos das leguminosas, festuca e azevém. A. latifolia não teve bom estabelecimento e sua participação foi de $0,84 \%$ no primeiro corte. L. subbiflorus teve uma boa participação no primeiro ano (37\%), mas desapareceu no segundo ano. L. uliginosus mostrou boa persistência, produzindo $1.400 \mathrm{~kg} / \mathrm{ha}$ de MS no outono/2001.
\end{abstract}

Palavras-chave: misturas, estabelecimento

\section{Response of Legumes (Adesmia, Lotus, Trifolium) in mixture with Tall Fescue}

\begin{abstract}
Overseeding temperate legumes is one of the most practices to increase the quantity, quality and sustainability of perennial pastures in Southern Brazil. During the years of 2000 and 2001 the response of six temperate legumes (Adesmia latifolia (wild), Lotus corniculatus, L. subbiflorus, L. uliginosus and Trifolium repens cv. Yi and cv. Regal) was evaluated in mixture with tall fescue (Festuca arundinacea). There was a period of 475 days between sowing date and the last cut and six cuts were made; on the autumn-winter/2000 only one cut was made, on the spring-summer, three cuts and on the autumn-winter/2001, two cuts. The intervals between cuts ranged between 43 and 91 days, being reduced in the warm season. During the total assay period, the average of the mixtures yielded $15038 \mathrm{~kg} / \mathrm{ha}$ of DM; in the warm season $54 \%$ of this total was produced, with an average growth rate of $46 \mathrm{~kg} / \mathrm{ha} / \mathrm{day}$ of DM. In the cold season of 2000 and 2001 this rate was of 22 and $24 \mathrm{~kg} / \mathrm{ha} /$ day of DM. The birdsfoot trefoil and white clover cv. Yi were the most productive legumes; the former was the best in the warm season (3500 kg/ha of DM) and the last participated with $86,3 \%$ in the mixture in the autumn-winter/2001, with $2300 \mathrm{~kg} /$ ha/day of DM. The mixtures containing these legumes presented the smallest quantity of weeds and produced 13663 and $11,184 \mathrm{~kg} / \mathrm{ha}$ of DM respectively, being $82 \%$ and $71 \%$ of these totals composed of legumes, fescue and ryegrass. A. latifolia did not have a good establishment and its contribution was only $0,84 \%$ in the first cut. The $L$. subbiflorus had a good establishment on the first year, but it disappeared from the mixture in the second year. L. uliginosus had a good establishment and persistence producing up to $1400 \mathrm{~kg} / \mathrm{ha}$ of DM in the autumn/2001.
\end{abstract}

Key Words: mixtures, establishment

\section{Introdução}

Um dos mais sérios problemas dos rebanhos gaúchos é a subalimentação em períodos mais frios do ano e, também, nos meses de transição entre os picos de crescimento das espécies de inverno e de verão.
Assim é no outono, quando as espécies de verão já estão encerrando seu ciclo, ou no início da primavera, quando as espécies de inverno encontram-se em fase de florescimento e formação de sementes. Essa condição se observa tanto em pastagens naturais quanto em pastagens monoespecíficas, anuais ou perenes.

\footnotetext{
1 Trabalho financiado pela Fundação de Amparo à Pesquisa do Estado do Rio Grande do Sul (Fapergs).

2 Eng.-Agr., Dra., Professora Titular do Instituto de Ciências Biológicas, Universidade de Passo Fundo (UPF), RS. Campus Universitário Bairro São José, Cep: 99001-970. E.mail: simone@upf.br

3 Eng. Agr., aluna do curso de Mestrado em Produção Vegetal, UPF.

${ }^{4}$ Acadêmica do Curso de C. Biológicas/UPF. Bolsista CNPq

5 Acadêmico de. C. Biológicas, UPF, bolsista Fapergs.

${ }^{6}$ Acadêmico de C. Biológicas, UPF.

7 Estatística, MSc., UPF. E.mail: cecchetti@upf.br
} 
Entre as opções para dirimir esse problema está o cultivo de misturas de gramíneas e leguminosas, hibernais ou estivais, anuais ou perenes. Pode-se optar pela formação de pastagens com espécies de inverno (normalmente leguminosas) misturadas com espécies de verão (gramíneas), ou estabelecer somente espécies de inverno. Em se tratando de leguminosas, as opções recaem sobre espécies de clima temperado, cujo centro de origem é o hemisfério Norte, especialmente a Ásia e a Europa.

A mais nobre das leguminosas para compor misturas para pastejo é o trevo-branco (Trifolium repens L.). No entanto, em condições de clima subtropical, essa espécie tem sua persistência comprometida pela ocorrência de verões quentes e secos. Isso promove elevada mortalidade de estolões, o que retarda seu crescimento no outono. Outra espécie comumente utilizada para compor pastagens mistas é o cornichão (Lotus corniculatus L.), cujo comportamento está bem esclarecido na região da Campanha do Rio Grande do Sul, onde forma mesclas com azevém (Lolium multiflorum Lam.) e trevo-branco. Contudo, entre suas limitações está a baixa tolerância a frios intensos, apresentando melhor adaptação em temperaturas amenas, ao redor de $24^{\circ} \mathrm{C}$. Outras leguminosas estão sendo introduzidas no Sul do Brasil, como o Lotus subbiflorus Lagasca e o L. uliginosus Schkuhr. Esse último apresenta elevada capacidade de estabelecimento em condições de má drenagem do solo, mas mostra escasso florescimento nas condições de fotoperíodo do sul do Brasil. Já o L. subbiflorus tem aparecido espontaneamente em pastagens nativas, provavelmente como impureza em lotes de sementes de outras espécies importadas do Uruguai.

Além das leguminosas domesticadas e utilizadas comercialmente, trabalhos estão sendo realizados no Sul do Brasil com a finalidade de avaliar o germoplasma nativo, cuja diversidade é enorme. Entre as leguminosas de inverno, destaca-se Adesmia DC. Trabalhos recentes, conduzidos em casa de vegetação, têm demonstrado que Adesmia latifolia, nativa do sul do Brasil, merece a continuidade dos estudos pelo seu elevado valor nutritivo, hábito estolonífero e comprovada capacidade de fixação de nitrogênio (Scheffer-Basso et al., 2001), além de ser hibernal. Todavia, na região do Planalto Médio do Rio Grande do Sul, não existem informações sobre seu desempenho.

A introdução das leguminosas pode ser feita em semeadura simultânea com gramíneas ou sobre pastagens já formadas, naturais ou não. No entanto, o ano em que são estabelecidas é especialmente crítico, pois suas sementes são pequenas e sofrem acirrada competição com plântulas de espécies invasoras. A coexistência é crucial para o sucesso de qualquer programa de melhoramento voltado ao aumento da produtividade de pastagens de gramíneas/leguminosas (Hill, 1990), e a compatibilidade pode ser medida, de acordo com Sanderson \& Elwinger (1999), pela produção da leguminosa na mistura.

Cerca de 50\% da área do Rio Grande do Sul é utilizada com a pecuária extensiva, feita em pastagens naturais. Noutras regiões, como o Planalto Médio, a atividade agrícola se faz basicamente com lavouras de soja (Glycine $\max$ (Linn.) Merril.) e milho (Zea mays L.); logo, a maior parte das áreas fica em pousio durante o inverno. No entanto, pequenos agricultores estão abandonando tal atividade e direcionando suas propriedades para produção de leite. Isso tem promovido a busca por informações sobre o desempenho e o manejo de espécies forrageiras, cujos trabalhos ainda são muito restritos a gramíneas anuais de inverno, como aveia (Avena sp.) e azevém.

Oobjetivo deste trabalho foi verificar o desempenho agronômico de leguminosas dos gêneros Adesmia, Lotus e Trifolium, em mistura com festuca (Festuca arundinacea Schreb.), espécie temperada perene com boa disponibilidade de sementes no comércio regional.

\section{Material e Métodos}

O ensaio foi conduzido no município de Passo Fundo, Rio Grande do Sul, coordenadas $28^{\circ} 15^{\prime} \mathrm{S}$ e $52^{\circ} 24^{\prime} \mathrm{W}, 687 \mathrm{~m}$ de altitude média e clima subtropical úmido (Cfa). Seis leguminosas (Adesmia latifolia, Lotus corniculatus cv. São Gabriel, L. subbiflorus cv. El Rincón, L. uliginosus cv. Maku, Trifolium repens $\mathrm{cv}$. Yi e cv. Regal) foram semeadas em $22 \mathrm{de}$ maio de 2000 com festuca. Os tratamentos foram distribuídos casualmente em blocos, com quatro repetições, em área de lavoura. O solo foi preparado mediante uma gradagem leve, após a dessecação com herbicida a base de glifosato. As parcelas tiveram 1,4 x 6 m, com um metro entre si e 1,5 m entre blocos. O solo (latossolo vermelho escuro distrófico) apresentava $\mathrm{pH}$ 5,9 e, por ocasião da semeadura, recebeu o equivalente a $300 \mathrm{~kg} / \mathrm{ha}$ de fertilizante NPK (5-25-20) nas linhas de semeadura das leguminosas. Um ano após a semeadura, foi aplicado o equivalente a $90 \mathrm{~kg} / \mathrm{ha}$ de $\mathrm{P}_{2} \mathrm{O}_{5}$, em superfície, a lanço, como adubação de manutenção. As leguminosas

R. Bras. Zootec., v.31, n.6, p.2197-2203, 2002 
foram inoculadas com rizóbio específico, peletizadas com calcário tipo filler e distribuídas manualmente em linhas distantes 0,20 m nas parcelas. Em seguida, a festuca foi distribuída superficialmente nas entrelinhas, a lanço, e levemente incorporada com ancinhos. As leguminosas foram semeadas nas densidades de $5 \mathrm{~kg} / \mathrm{h}$ a para Lotus e Adesmia e 2,5 kg/ha para trevo-branco. Apenas as sementes de Adesmia foram previamente escarificadas através de imersão em água a $100^{\circ} \mathrm{C}$ durante cinco minutos. O sistema de manejo preconizado foi o de corte das parcelas sempre que a festuca atingisse 20 a $25 \mathrm{~cm}$ de altura. As avaliações foram realizadas por meio de corte da forragem rente ao solo, com tesoura, sendo retirada uma amostra/parcela/corte, em área de $0,25 \mathrm{~m}^{2}(0,50$ x $0,50 \mathrm{~m}$ ), demarcada com um quadrado metálico. Após a amostragem, as parcelas eram roçadas mecanicamente, deixando-se uma resteva de aproximadamente $8 \mathrm{~cm}$, para garantir a rebrota do restante da área das parcelas. O material vegetal presente após a roçada era retirado das parcelas com auxílio de ancinhos. No laboratório, as amostras foram separadas nos seguintes componentes: festuca, leguminosas semeadas, invasoras, azevém e material morto. Esses componentes eram conduzidos à estufa $\left(70^{\circ} \mathrm{C}\right)$ e pesados posteriormente. A disponibilidade de forragem foi obtida através da soma de todos os componentes, com exceção do material morto, e transformada em $\mathrm{kg} / \mathrm{ha}$ de MS. A análise estatística foi realizada através do programa SAS, no modelo de dados longitudinais para medidas repetidas (Collins et al., 1996).

\section{Resultados e Discussão}

\section{Condições climáticas e manejo do ensaio}

$\mathrm{Na}$ época do estabelecimento do ensaio, final do outono/2000, o clima caracterizou-se por temperaturas médias de $14^{\circ} \mathrm{C}$, próximo à média normal, calculada $\mathrm{a}$ partir de observações dos últimos trinta anos (Figura 1); no entanto, o inverno foi rigoroso, sendo o mês de julho mais frio que o normal, com fortes geadas e temperaturas abaixo de zero, chegando a $-3,5^{\circ} \mathrm{C}$. No restante do período experimental, as temperaturas foram próximas à normalidade. Quanto às precipitações pluviométricas, o inverno de 2000 apresentou-se seco, especialmente em agosto e setembro, com médias inferiores às normais para o período, o que se repetiu no inverno de 2001. A pouca precipitação ocorrida em maio e o inverno frio prejudicaram o estabelecimento das espécies introduzidas, especial- mente A. latifolia, que também tiveram forte concorrência do azevém, espontâneo na área. No entanto, as condições climáticas da primavera-verão foram excepcionais para a produção de forragem.

A duração do ensaio foi de 475 dias entre a semeadura e o último corte, sendo efetuados seis cortes. No outono-inverno do primeiro ano, foi feito um corte; já, na primavera-verão, foram realizados três e, no outono-inverno do ano seguinte, dois cortes. Os intervalos de cortes variaram entre 43 e 91 dias, sendo menores na estação estival (Tabela 1).

Produção de forragem e composição botânica

No total do período experimental, obtiveram-se, na média das misturas, $15.038 \mathrm{~kg} / \mathrm{ha}$ de MS, sendo que, na primavera-verão, foram produzidos cerca de $54 \%$ desse total, com uma taxa de crescimento média de $46 \mathrm{~kg} / \mathrm{ha} / \mathrm{dia}$ de MS. Nos meses de outono-inverno de 2000 e 2001, foram obtidas taxas de 22 e $24 \mathrm{~kg} / \mathrm{ha} / \mathrm{dia}$
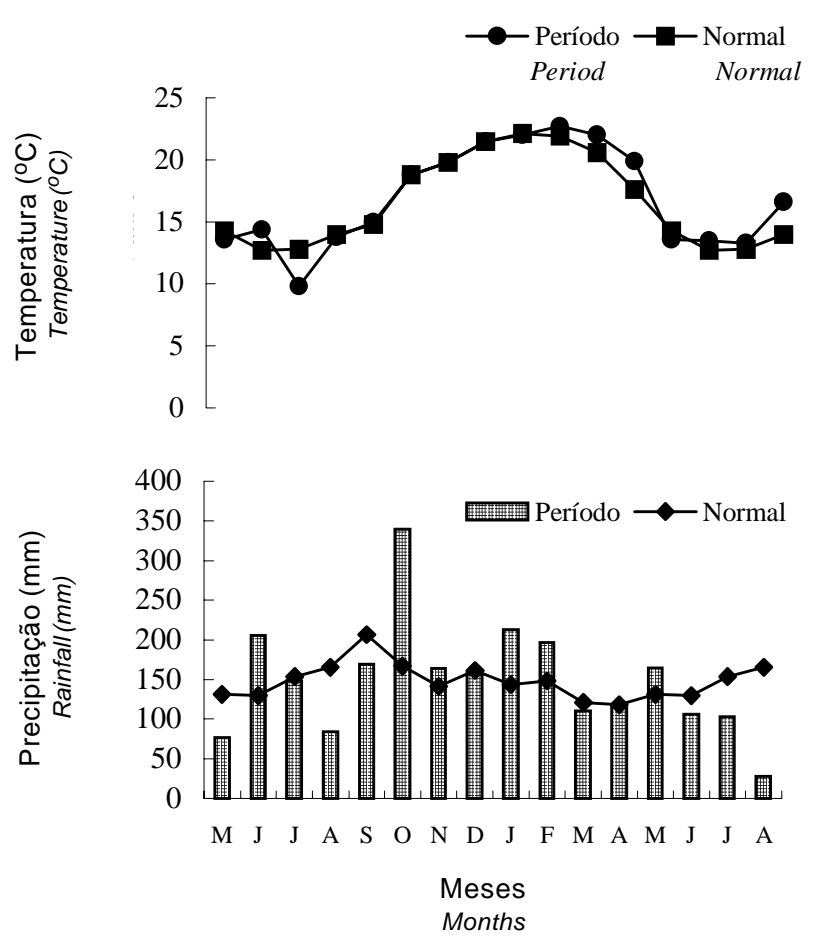

Figura 1 - Temperaturas médias e precipitação mensal do período experimental (maio/2000-agosto/ 2001) e as médias normais (30 anos). Centro Nacional de Pesquisa de Trigo/ Embrapa Passo Fundo (http//www.cnpt.embrapa. com. br)

Figure 1 - Mean temperature and monthly rainfall during the experimental period (May/2000 - August/2001) and the normal means.

R. Bras. Zootec., v.31, n.6, p.2197-2203, 2002 
de MS, respectivamente, demonstrando a resposta das espécies componentes das misturas, gramíneas, leguminosas e invasoras de verão às baixas temperaturas dessas estações (Tabela 1). Nos dois anos, os períodos de outono-inverno foram responsáveis por 17 e $29 \%$ do total da forragem produzida, que foi de cerca de $10 \mathrm{t} /$ ha de MS, considerando-se as espécies semeadas.

A análise estatística mostrou efeito da leguminosa presente na mistura $(\mathrm{P}<0,05)$ sobre a disponibilidade de MS. As diferenças entre as misturas foram evidentes a partir de janeiro de 2001 (terceiro corte), quando o azevém havia finalizado seu ciclo (Tabela 2). Nos dois primeiros cortes, entre 60 a $90 \%$ da MS foram provenientes do azevém, não havendo diferença significativa $(\mathrm{P}>0,05)$ entre as misturas. Obtiveram-se, em média, 2.581 e $2.120 \mathrm{~kg} / \mathrm{ha}$ de MS em 6/9/00 e 20/10/00, respectivamente. A partir dessa data, as diferenças entre as misturas tornaram-se evidentes, com aquela que tinha cornichão acumulando, em 91 dias, cerca $3.500 \mathrm{~kg} / \mathrm{ha}$ de MS (Figura 2). Esse valor foi superior ao obtido $(2.273 \mathrm{~kg} / \mathrm{ha}$ de MS) por Viégas \& Saibro (1998) com cornichão em mistura com gramíneas na primavera de 1989, em Eldorado do Sul. Embora não tenha havido diferença significativa com o L. uliginosus, quanto ao total acumulado, verificou-se uma diferença importante quanto à composição botânica dessas misturas. Enquanto o cornichão esteve presente em $80 \%$ da forragem disponível, na mistura de L. uliginosus $71 \%$ eram invasoras, especialmente guanxuma (Sida rhombifolia Linn). A mistura de cornichão sempre esteve entre as mais produtivas (13.663 kg/ha) até o final do ensaio, destacando-se também pela menor quantidade relativa de espécies invasoras no período de verão e do outono do segundo ano (Tabela 2), o que é desejável. Isso demonstra que a estação primaveril, cujas temperaturas médias regionais estão entre $20 \mathrm{e}$ $25^{\circ} \mathrm{C}$, favorece o crescimento dessa espécie e que a região do Planalto Médio do Rio Grande do Sul é adequada ao seu cultivo.

Em trabalho de Santinaque \& Carámbula (1981), a mistura contendo cornichão também se destacou como a de menor incidência de invasoras. Esses autores consideram o cornichão como uma leguminosa temperada, mas de crescimento estival, o que pode explicar sua efetividade na competição com invasoras de verão e excelente desempenho numa região de temperaturas amenas.

Apesar de o cornichão ser considerado uma espécie de crescimento inicial lento, neste trabalho a espécie apresentou um excelente acúmulo de matéria seca no primeiro ano, destacando-se das demais. Seu desempenho foi favorecido pela pouca competição exercida pela festuca, similar ao constatado por Short \& Carlson (1989), que verificaram melhor estabelecimento do cornichão quando associado com cultivares tardios de capim-dos-pomares (Dactylis glomerata L.).

Entre as espécies de Lotus, L. uliginosus também mostrou um bom desempenho nas misturas; seu melhor desempenho foi no outono/2001, num total de $1400 \mathrm{~kg} / \mathrm{ha}$ de MS acumulados em 45 dias, ao passo

Tabela 1 - Média da disponibilidade total de matéria seca (MS) total, rebrota e taxa de crescimento (MS) das misturas Table 1 - Average total dry matter (DM), regrowth and growth rate of the mixtures

\begin{tabular}{|c|c|c|c|c|}
\hline $\begin{array}{l}\text { Estação } \\
\text { Season }\end{array}$ & $\begin{array}{l}\text { Data dos cortes } \\
\text { Cutting date }\end{array}$ & $\begin{array}{l}\text { Crescimento e rebrota } \\
\text { Growth and regrowth }\end{array}$ & $\begin{array}{c}\text { Disponibilidade de MS } \\
\text { DM availability }\end{array}$ & $\begin{array}{c}\text { Taxa de crescimento } \\
\text { Growth rate }\end{array}$ \\
\hline & & $\begin{array}{c}\text {-dias- } \\
\text { days }\end{array}$ & $\begin{array}{c}\text { - } \mathrm{kg} / \mathrm{ha}-{ }_{\mathrm{kg} / \mathrm{ha}} \\
\end{array}$ & $\begin{array}{c}-\mathrm{kg} / \mathrm{ha} / \mathrm{dia}- \\
\mathrm{kg} / \mathrm{ha} / \text { day }\end{array}$ \\
\hline $\begin{array}{l}\text { Outono-Inverno/00 } \\
\text { Autumn-Winter } / 00\end{array}$ & $06 / 09 / 00$ & Total $=117$ & 2.587 & 22,11 \\
\hline $\begin{array}{l}\text { Primavera-Verão 00/01 } \\
\text { Spring-Summer 00/01 }\end{array}$ & $\begin{array}{l}20 / 10 / 00 \\
19 / 01 / 01 \\
03 / 03 / 01\end{array}$ & $\begin{array}{c}\text { Total }=178 \\
\text { Rebrota }=44 \\
\text { Rebrota }=91 \\
\text { Rebrota }=43\end{array}$ & 8.127 & 45,66 \\
\hline $\begin{array}{l}\text { Outono-Inverno/01 } \\
\text { Autumn-Winter/01 }\end{array}$ & $\begin{array}{l}31 / 05 / 01 \\
30 / 08 / 01\end{array}$ & $\begin{array}{c}\text { Total }=180 \\
\text { Rebrota }=89 \\
\text { Rebrota }=91\end{array}$ & 4.321 & 24,00 \\
\hline $\begin{array}{l}\text { Total (espécies desejá } \\
\text { Total (cultivated species }\end{array}$ & $\begin{array}{l}\text { is }+ \text { invasoras) } \\
\text { weeds) }\end{array}$ & 475 & 15.038 & 31,66 \\
\hline
\end{tabular}

R. Bras. Zootec., v.31, n.6, p.2197-2203, 2002 
Tabela 2 - Disponibilidade de matéria seca total, de forragem (espécies desejáveis + invasoras) e composição botânica das misturas

Table 2 - Total dry matter availability, forage (cultivated species + weeds) and botanical composition of the mixtures

\begin{tabular}{|c|c|c|c|c|c|c|c|}
\hline \multirow[t]{2}{*}{$\begin{array}{l}\text { Período } \\
\text { Period }\end{array}$} & \multirow[t]{2}{*}{$\begin{array}{c}\text { Componentes } \\
\text { Components }\end{array}$} & \multicolumn{6}{|c|}{$\begin{array}{l}\text { Leguminosas nas misturas } \\
\text { Legumes in the mixtures }\end{array}$} \\
\hline & & A.L & L.C & L.S & L.U & Yi & Regal \\
\hline \multirow[t]{9}{*}{ 06/09/00 } & Total (kg/ha) & $3.013 \mathrm{a}$ & $2.416 \mathrm{a}$ & $2.660 \mathrm{a}$ & $2.398 \mathrm{a}$ & $2.726 \mathrm{a}$ & $2.309 a$ \\
\hline & Azevém (\%) & 93,59 & 82,10 & 93,50 & 80,37 & 80,06 & 85,48 \\
\hline & Italian ryegrass & & & & & & \\
\hline & Festuca (\%) & 0,35 & 0,86 & 0,60 & 1,21 & 1,06 & 2,02 \\
\hline & Tallfescue & & & & & & \\
\hline & Leguminosa $(\%)$ & 0,26 & 4,05 & 0,10 & 1,67 & 4,13 & 2,34 \\
\hline & Legume & & & & & & \\
\hline & Invasoras (\%) & 5,80 & 12,99 & 5,80 & 16,75 & 14,75 & 10,16 \\
\hline & Weeds & & & & & & \\
\hline \multirow[t]{5}{*}{$20 / 10 / 00$} & Total (kg/ha) & $1.556 \mathrm{a}$ & $1.797 \mathrm{a}$ & $1.819 \mathrm{a}$ & $2.924 \mathrm{a}$ & $2.186 a$ & $2.435 \mathrm{a}$ \\
\hline & Azevém(\%) & 61,92 & 59,93 & 94,94 & 92,69 & 81,41 & 92,41 \\
\hline & Festuca $(\%)$ & 2,82 & 1,08 & 0,68 & 0,47 & 0,09 & 0,04 \\
\hline & Leguminosa $(\%)$ & 0,03 & 15,39 & 1,88 & 2,70 & 10,74 & 0,86 \\
\hline & Invasoras (\%) & 35,23 & 23,60 & 2,50 & 4,14 & 7,76 & 6,69 \\
\hline \multirow[t]{4}{*}{$19 / 01 / 01$} & Total (kg/ha) & $2.024 b$ & $4.124 \mathrm{a}$ & $2.712 b$ & $2.952 \mathrm{ab}$ & $2.460 \mathrm{~b}$ & $1.994 b$ \\
\hline & Festuca $(\%)$ & 33,91 & 8,68 & 22,46 & 5,80 & 5,88 & 30,25 \\
\hline & Leguminosa $(\%)$ & 0,84 & 80,17 & 35,27 & 23,00 & 35,62 & 20,79 \\
\hline & Invasoras $(\%)$ & 65,25 & 11,15 & 42,27 & 71,20 & 58,5 & 48,96 \\
\hline \multirow[t]{4}{*}{ 03/03/01 } & Total (kg/ha) & $2.357 b$ & $3.533 \mathrm{ab}$ & $3.334 \mathrm{ab}$ & $4.346 \mathrm{a}$ & $2.801 \mathrm{ab}$ & $3.402 \mathrm{ab}$ \\
\hline & Festuca $(\%)$ & 45,13 & 14,4 & 20,36 & 14,74 & 7,41 & 31,84 \\
\hline & Leguminosa $(\%)$ & 0,00 & 68,6 & 19,48 & 32,47 & 40,74 & 12,00 \\
\hline & Invasoras (\%) & 54,87 & 17,00 & 60,16 & 52,79 & 51,85 & 56,16 \\
\hline \multirow[t]{4}{*}{$31 / 05 / 01$} & Total (kg/ha) & $2.581 \mathrm{a}$ & $2.327 \mathrm{a}$ & $2.312 \mathrm{a}$ & $2.451 \mathrm{a}$ & $2.774 \mathrm{a}$ & $2.705 a$ \\
\hline & Festuca $(\%)$ & 58,02 & 16,79 & 48,76 & 25,88 & 14,28 & 29,08 \\
\hline & Leguminosa $(\%)$ & 0,00 & 54,08 & 0,00 & 5,54 & 51,11 & 8,83 \\
\hline & Invasoras (\%) & 41,98 & 29,13 & 51,24 & 68,58 & 34,61 & 62,09 \\
\hline \multirow[t]{4}{*}{$30 / 08 / 01$} & Total (kg/ha) & $967 \mathrm{c}$ & $2.333 \mathrm{ab}$ & $1.228 b c$ & $1.689 \mathrm{ab}$ & $2.697 \mathrm{a}$ & $1.882 \mathrm{abc}$ \\
\hline & Festuca $(\%)$ & 88,69 & 20,26 & 67,82 & 32,59 & 12,35 & 45,49 \\
\hline & Leguminosa $(\%)$ & 0,39 & 63,00 & 0,00 & 44,99 & 86,3 & 51,99 \\
\hline & Invasoras (\%) & 10,92 & 16,74 & 32,18 & 22,42 & 1,35 & 2,52 \\
\hline Total MS & & 12.498 & 16.530 & 14.065 & 16.760 & 15.644 & 14.727 \\
\hline \multicolumn{8}{|l|}{ Total DM } \\
\hline Forragem & & 7.972 & 13.663 & 9.133 & 9.782 & 11.184 & 9.716 \\
\hline Forage & & & & & & & \\
\hline
\end{tabular}

Médias seguidas por letras iguais, nas linhas, não diferem pelo teste Tukey ( $>0,05)$ (Means followed by the same letter, within a line, did not differ by Tukey test).

A.L (Adesmia latifolia), L.C (Lotus corniculatus), L.S (L. subbiflorus), L.U (L. uliginosus), Yi (Trifolium repens cv. Yi), Regal (T. repens cv. Regal).

que, no inverno de 2001, participou com $45 \%$ da forragem acumulada, produzindo $760 \mathrm{~kg} / \mathrm{ha}$ de MS (Tabela 2). Observando-se o incremento de forragem entre maio e agosto/2001, L. uliginosus foi superior ao cornichão, sugerindo maior adaptação ao frio (Figura 2). O comportamento dessa espécie, em termos de produção de forragem e de persistência, através da expansão vegetativa e da sobrevivência dos indivíduos, sugere uma boa adaptação à região de estudo, apesar de não ter florescido. Isso foi evidenciado no Brasil por outros pesquisadores, como Paim \& Riboldi (1991). Segundo esses autores, é necessário grande esforço para adaptação e seleção de material mais adequado às condições do Rio Grande do Sul, onde seu uso tem sido restringido pela baixa produção e difícil colheita de sementes, aliada ao

\section{R. Bras. Zootec., v.31, n.6, p.2197-2203, 2002}


esparso ou, até mesmo, à ausência de florescimento no ano do estabelecimento. Monteiro (1981), na Depressão Central, RS, observou florescimento tardio da cv. Maku apenas aos 233 dias após a semeadura. Já Oliveira \& Paim (1990) constataram maior precocidade (florescimento aos 188 dias) em material previamente selecionado em Lages, SC, indicando uma resposta à seleção.

Quanto ao L. subbiflorus, sua contribuição foi de, no máximo, 35\% na mistura, em janeiro de 2001, acumulando $950 \mathrm{~kg} / \mathrm{ha}$ de MS. A espécie não se fez presente a partir do outono do segundo ano, demonstrando sua duração anual e indicando necessidade de manejo que permita sua ressemeadura natural.

O trevo-branco mostrou uma excelente adaptação ao clima da região, especialmente o cv. Yi, que, ao final do segundo inverno, contribuiu em $86 \%$ da forragem da mistura, em relação ao cv. Regal, com $52 \%$ (Tabela 2). No total do período experimental, o cv. Yi produziu cerca de $6.000 \mathrm{~kg} / \mathrm{ha}$ de MS, o que significa $12 \mathrm{~kg} / \mathrm{ha} / \mathrm{dia}$ de MS, ao passo que o cv. Regal produziu aproximadamente $2.100 \mathrm{~kg} / \mathrm{ha}$ de MS no mesmo período. Apesar do excelente desempenho do cv. Yi, sua contribuição na mistura excedeu ao percentual desejável em nível de fazenda, no que diz respeito ao risco de timpanismo. Tais considerações também foram feitas por Elgersma et al. (1998), que destacam o fato de que, sob corte, o trevo-branco rapidamente se torna dominante, especialmente quando não se utiliza N mineral, mas que, sob pastejo, quando esse elemento retorna parcialmente sob fezes e urina e os estolões podem ser removidos ou danificados pelos animais, as proporções da leguminosa são muito menores. Um dos fatores que contribuíram para seu desempenho foi o regime pluviométrico ocorrido na primavera-verão, uma vez que essa espécie requer umidade para manter sua expansão através do enraizamento dos estolões. Sua excelente expansão na primavera-verão reduziu a presença de plantas invasoras. No inverno do segundo ano, as misturas contendo trevo-branco apresentaram os menores percentuais de invasoras (Tabela 2). Se comparado com o cornichão, o pico de acúmulo de MS foi distinto nessas leguminosas: o cornichão confirmou sua aptidão como leguminosa primaveril, ao passo que o trevo-branco teve maior participação na estação de outono-inverno(Figura 2), tal como foi verificado por Formoso \& Allegri (1982) no Uruguai. Os cultivares de trevobranco mostraram participação crescente nas misturas, enquanto o cornichão decresceu seu percentual (Figura 2). Mesmo assim, essa espécie foi responsável por cerca de

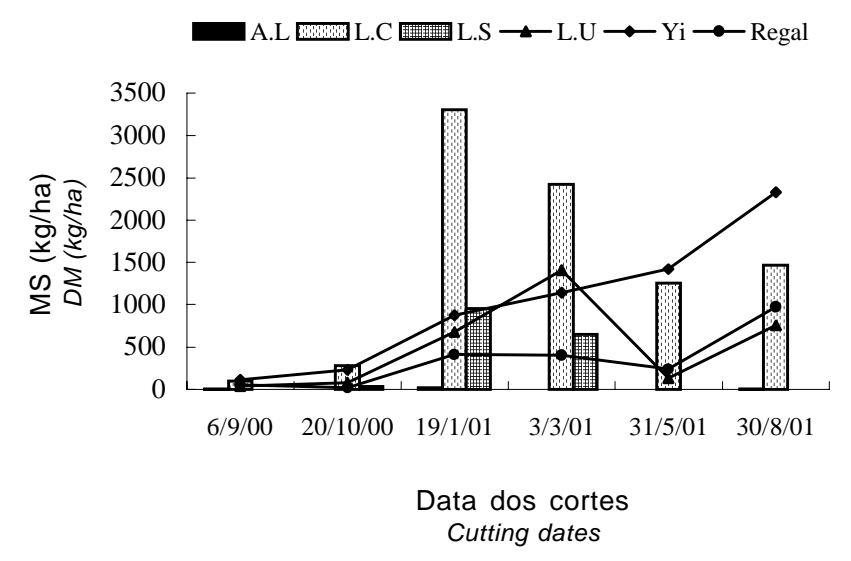

Figura 2 - Disponibilidade de forragem de Adesmia latifolia (A.L), Lotus corniculatus (L.C), L. subbiflorus (L.S), L. uliginosus (L.U), Trifolium repens cv. Yi (Yi) e T. repenscv. Regal (Regal).

Figure 2 - Forage availability of Adesmia latifolia (A.L), Lotus corniculatus (L.C), L. subbiflorus (L.S), L. uliginosus (L.U), Trifolium repens cv. Yi (T.R Yi) e T. repens cv. Regal (T.R Regal).

$8.800 \mathrm{~kg} / \mathrm{ha}$ de MS na mistura ao longo de 475 dias, indicando boa tolerância ao manejo de corte.

Entre as gramíneas forrageiras presentes na biomassa estimada, o azevémespontâneo teve expressiva produção de MS no outono/inverno do ano de estabelecimento das misturas, confirmando seu valorno planejamento forrageiro dos rebanhos no sul do Brasil. No segundo ano, essa espécie não estava presente na área, já que o manejo imposto não permitiu sua ressemeadura. Todavia, é interessante sua presença, especialmente no ano de implantação das espécies perenes, uma vez que, apesar de exercer competição com essas, fornece forragem sabidamente de ótima qualidade, enquanto as demais ainda não acumulam expressivas produções de matéria seca. A festuca mostrou-se pouco competitiva em presença de trevo-branco e cornichão (Figura 3), concordando com os resultados de Haussman et al. (1981), que verificaram o lento desenvolvimento dessa espécie em presença do cornichão, alcançando completo desenvolvimento somente no segundo ano.

Segundo Fribourg et al. (1981), a festuca produz bem na primavera, é relativamente dormente no verão e produz moderadas quantidades de forragem no outono e inverno, quando as temperaturas são favoráveis. É importante salientar que um dos motivos para o lento crescimento da festuca deve ter sido a ausência de adubações nitrogenadas em cobertura, o que reduziu sua capacidade competitiva. Viégas \& Saibro (1998) também não obtiveram um bom estabe- 


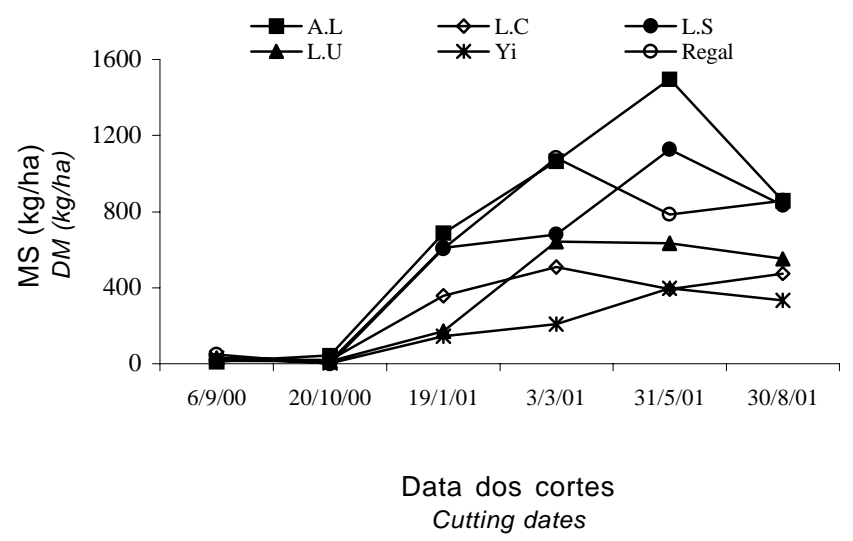

Figura 3 - Disponibilidade de forragem de festuca $(\mathrm{kg} / \mathrm{ha})$ na mistura com Adesmia latifolia (A.L), Lotus corniculatus (L.C), L. subbiflorus (L.S), L. uliginosus (L.U), Trifolium repens $\mathrm{cv}$. Yi (Yi) e T. repens cv. Regal (Regal).

Figure 3 - Forage availability of tall fescue in the mixture with Adesmia latifolia (A.L), Lotus corniculatus (L.C), L. subbiflorus (L.S), L. uliginosus (L.U), Trifolium repens cv. Yi (Yi) e T. repens cv. Regal (Regal).

lecimento e desempenho de festuca nas condições de Eldorado do Sul, atribuindo isso ao fato de que as temperaturas altas comuns dessa região não permitem que essa espécie entre em dormência no verão e, com isso, não acumulam reservas suficientes para um rápido rebrota no outono.

\section{Conclusões}

Adesmia latifolia apresenta limitações no estabelecimento por meio de sementes, em solos bem drenados, devendo ser analisada a possibilidade de cultivo restrito a áreas baixas, sem limitação de umidade ou sobre pastagens já estabelecidas.

O cornichão mostra-se como boa opção para obtenção de forragem na primavera, especialmente no ano do estabelecimento das misturas.

É interessante que seja introduzida uma gramínea anual, como azevém, para se obter elevada produção de forragem no ano do estabelecimento.

A elevada capacidade de competição do trevobranco, sob adequadas condições de umidade, conduz à necessidade de um manejo criterioso de forma a permitir o adequado crescimento da gramínea associada e evitar riscos de timpanismo.

Lotus subbiflorus deve ser diferido para que ocorra ressemeadura natural, enquanto L. uliginosus apresenta limitações na produção de sementes, por não florescer na região de estudo.

\section{Literatura Citada}

COLLINS, R.P.; FOTHERGILL, M.; POTTER, J.F. et al. The use of repeated-measurement analysis to describe the over wintering of white clover cultivars. Grass and Forage Science, v.51, p.116-120, 1996.

ELGERSMA, A.; NASSIRI, M.; SCHLEPERS, H. Competition in perennial ryegrass-white clover mixtures under cutting. 1. Dry-matter yield, species composition and nitrogen fixation. Grass and Forage Science, v. 53, p. 353-366, 1998.

FORMOSO, F.A.; ALLEGRI, M. Evaluación de mezclas forrajeras en la Zona Noreste II. Comportamiento agronómico sobre una pradera parda. Investigaciones Agronómicas, v.3, p.52-56, 1982.

FRIBOURG, H.A.; MCLAREN, J.B.; CARLISE, R.J. Increase productivity and extending grazing season of Cynodon pastures for steers with $\mathrm{N}$ and overseedings of Trifolium and Festuca in the Southeastern U.S.A. In: INTERNATIONAL GRASSLAND CONGRESS, 14., 1981, Lexington. Proceedings...Lexington: Westwiew Press, 1981.p.714-716.

HAUSMANN, G.; PAOLETTI, R.; LOCATELli, C. Simple mixtures for dry mountain regions: relations between tall fescue and birdsfoot trefoil during five years. In: INTERNATIONAL GRASSLAND CONGRESS, 14., 1981, Lexington. Proceedings... Lexington: Westwiew Press, 1981. p.378-380.

HILL, J. The three Cs-competition, coexistence and coevolution - and their impact on the breeding of forage crop mixtures. Theoretical and Applied Genetics, v.79, p.168-176, 1990.

MONTEIRO, I.D. Teste de progênie de policruzamento de Lotus uliginosus Schkuh. Porto Alegre: Universidade Federal do Rio Grande do Sul, 1981. 118p. Dissertação (Mestrado em Fitotecnia) - Universidade Federal do Rio Grande do Sul, 1981.

OLIVEIRA, J.C.P.; PAIM, N.R. Teste de progênies em linha de seleção materna de duas espécies do gênero Lotus. Pesquisa Agropecuária Brasileira, v.25, p.461-467, 1990.

PAIM, N.R.; RIBOLDI, J. Competição entre espécies e cultivares do gênero Lotus L. Pesquisa Agropecuária Brasileira, v.26, p.1699-1704, 1991.

SANDERSON, M.A.; ELWINGER, G.F. Grass species and cultivars effects on establishment of grass-white clover mixtures. Agronomy Journal, v.91, p.889-897, 1999.

SANTIÑAQUE, F.; CARÁMBULA, M. Productividad y comportamiento de distintas mezclas forrajeras. Investigaciones Agronómicas, v.2, p.16-21, 1981.

SCHEFFER-BASSO, S.M.; JACQUES, A.V.; DALL' AGNOL, M. et al. Disponibilidade e valor nutritivo de forragem de leguminosas nativas (Adesmia DC.) e exóticas (Lotus L.). Revista Brasileira de Zootecnia, v.30, p.975-982, 2001.

SHORT, K.E.; CARLSON, I.T. Bi-directional selection for birdsfoot trefoil-compatibility traits in orchard grass. Crop Science, v.29, p.1131-1136, 1989.

VIÉGAS, J.; SAIBRO, J.C. de. Proteína bruta em misturas de cornichão mais festuca ou faláris. In: REUNIÓN DEL GRUPO TÉCNICO REGIONAL DEL CONO SUR EN MEJORAMIENTO Y UTILIZACIÓN DE LOS RECURSOS FORRAJEROS DEL ÁREA TROPICAL Y SUBTROPICAL: GRUPO CAMPOS, 14., 1994, Tacuarembó. Anales.... Salto: INIA, 1998. p. 61-63.

Recebido em: 02/01/02 Aceito em: 24/07/02

R. Bras. Zootec., v.31, n.6, p.2197-2203, 2002 